\title{
Influence of wet chemistry treatment on the mechanical performance of natural fibres
}

\author{
Mateusz Koziol*, Aleksandra Bogdan-Wlodek, Jerzy Myalski, Jakub Wieczorek \\ Silesian University of Technology, Faculty of Materials Engineering and Metallurgy, ul. Krasinskiego 8, 40-019 Katowice, Poland \\ "Corresponding author: e-mail: Mateusz.Koziol@polsl.pl
}

\begin{abstract}
The paper presents determination of the effect of various chemical treatment on the strength of 288 tex jute yarn arisen from the plain weave fabric produced by LENTEX, Poland. The yarn was put to alternative treatments in: $\mathrm{NaOH}$ and $\mathrm{KOH}$ water solutions with various concentration (from 1 to $15 \%$ ) and treatment duration (from 0.5 to 6 hours), vinyl acetate, methanol and toluene diisocyanate. After the treatment it was put to tensile tests. Yarn diameter and elementary fibre twist angle were also measured using MICRO PROF FRT optical profilographometer. The SEM micro-photographs have also been performed in order to evaluate the structural changes of the yarn after the treatment.

Optimal conditions of alcali-treatment are: $5 \%$ concentration and $2 \mathrm{~h}$ duration for $\mathrm{NaOH}, 3 \%$ concentration and $4 \mathrm{~h}$ duration for $\mathrm{KOH}$. Such treatments give a growth in yarn rupture force up to $10 \%$ and they are well applicable in composite materials manufacturing. Also interaction with vinyl acetate and toluene diisocyanate has practically not negative influence on the mechanical performance of the yarn. Two effects were observed which can explain the influence of chemical treatment on mechanical performance of jute yarn: swelling and change in the orientation of elementary fibres.
\end{abstract}

Keywords: natural fibres, jute fibres, surface treatment, mechanical performance, fibre reinforced composites.

\section{INTRODUCTION}

Vegetable natural fibres as a reinforcing material for polymer matrix composites mark origin from renewable source and very low noxiousness for the environment - as a material and as a waste as well ${ }^{1,2}$. The disadvantage of natural fibres ist the relatively weak mechanical and elastic performance, caused by the strongly stochastic character of their superstructure (yarn) and rather low efficiency in coupling with matrix resins. It results in weak mechanical performance of manufactured composites. Numerous research - technological studies conducted by various centres aim at an improvement of the properties of the natural fibre reinforced composites ${ }^{3-7}$. It is mainly the improvement in the quality of coupling on fibre - matrix interface that is aimed. The improvement is obtained chiefly by the chemical ${ }^{4,5}$ or physical ${ }^{6,7}$ activation of the outer surface of the fibres compounding the yarn.

The paper concerns the determination of the effect of various chemical treatment on the strength of a jute yarn skein (Fig.1). The surface interaction of some chemical compounds may bring the changes in yarn structure and may affect its properties. It is necessary to evaluate what changes occur after certain treatment type and what is their degree. The range of the study contains the research of the effect of chemical treatment on the rupture force of jute yarn skeins taken from fabrics for composite reinforcements.

The applied substances (jute fabric, $\mathrm{NaOH}$ and $\mathrm{KOH}$ water solutions, methanol, vinyl acetate, toluene diisocyanate) have been taken under consideration within the study, because they are simply available and relatively cheap. It enables them to be used by various composite manufacturers - also some relatively small companies.

Tensile tests on the yarn skeins, firstly put to treatment in: water solutions of $\mathrm{NaOH}$ and $\mathrm{KOH}$, methanol, toluene diisocyanate and vinyl acetate, were made. Treatment with chemical compounds is in assumption to increase the yarn wettability with liquid polyester resin and thus

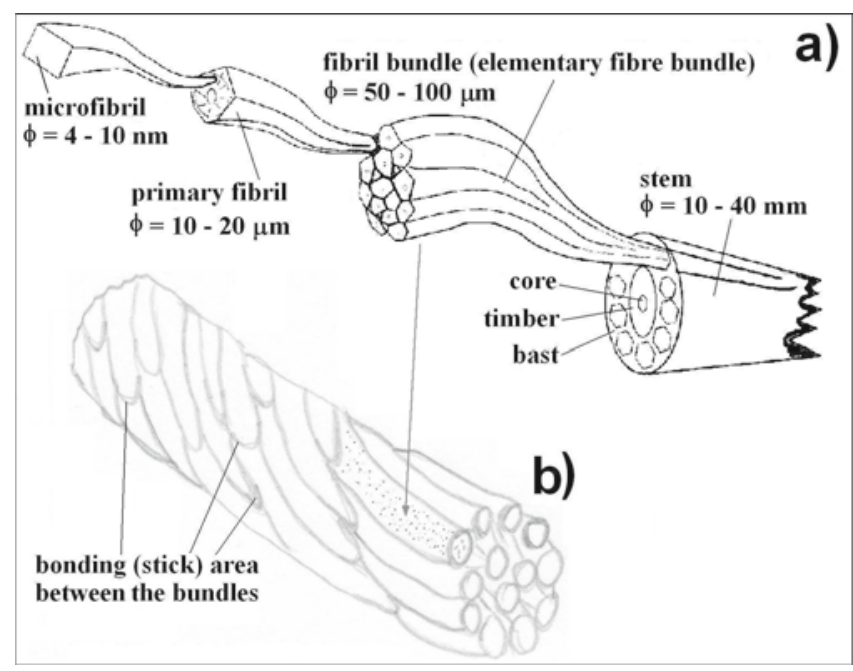

Figure 1. Illustration of the sub-structural "levels" in a plant stem (a) [8] and the scheme of a yarn skein (b)

improve the quality of coupling on a fibre - matrix interface, which gives the improvement in technological and mechanical properties of composites. The evaluation of: fibre wettability with the resin, quality of coupling between the components and mechanical properties of the composites is an object of the other research studies. The present study is part of the research program concerning a possibility of application of the natural fibres in composite materials technology.

\section{EXPERIMENTAL}

\section{Materials}

The investigations have been conducted on the yarn skeins pulled out from jute plain weave fabric, area weight $350 \mathrm{~g} / \mathrm{m}^{2}$, produced by LENTEX company, Poland. The skeins are similarly densificated into weft and warp directions within the fabric. The fabric is presently available in commercial market. The yarn density of the skeins 
is 288 tex. The spinning process demands application of special wax finish, which could have remained in low amount on the material. Polyester resin is planned to be used as a matrix of the composites basing on this fabric.

Sheets of the jute fabric were put to alternative treatments in the following substances: 1) $\mathrm{NaOH}$ water solution - various concentration and treatment duration (see Table 1, Fig.2a and 3a), 2) $\mathrm{KOH}$ water solution - various concentration and treatment duration (see Table 1, Fig.2b and 3b), 3) vinyl acetate, 4) methanol, 5) toluene diisocyanate. All the compounds have a polar character. After the treatment in $\mathrm{NaOH}$ and $\mathrm{KOH}$ solutions the sheets were put to the wash in water, neutralization in $1 \% \mathrm{HCl}$ water solution and secondary wash in water. Next they were exsiccated at $40^{\circ} \mathrm{C}$ with the provided unbounded dripping. Alternatively, after treatment with methanol and vinyl acetate the sheets were exsiccated at $30^{\circ} \mathrm{C}$, while after the treatment with toluene diisocyanate - in w $25^{\circ} \mathrm{C}$, also with provided unbounded dripping. Each treatment was carried on 2 sheets. After the exsiccation process the yarn skeins of about $40 \mathrm{~cm}$ long were pulled out of the sheets into the warp direction. 10 specimens for each type of the treatment were prepared ( 5 specimens from each of two sheets).

\section{Measurements}

Tensile tests were made using Intron 4469 tester, with $5 \mathrm{kN}$ measuring head ( $0.1 \mathrm{~N}$ measurement accuracy). Strain rate was set at $10 \mathrm{~mm} / \mathrm{min}$. The specimens were the yarn skeins with the tips rolled and wrapped with polymer tape on $50 \mathrm{~mm}$ section (it protected the yarn against being broken between the tester's chuck jaws), fixed in tester's chucks. The length of a gauge base (section between tester's chucks) was $100 \mathrm{~mm}$. All the tested specimens have broken within the gauge base.

The tests of yarn diameter and determination of the elementary fibre bundles twist angle were made with the use of optical profilographometer Micro Prof FRT, at about 94 x magnification. The method of the measurements is precisely described within the former study? A scheme of the twist angle concept is presented in Fig. 4. The concepts "elementary fibre bundle" and "yarn skein" are explained in the Fig. 1.

Hitachi S-3400N scanning electron microscope was used in additional observations of the yarn structure and elementary cellulose fibre bundles. The microphotographs are introduced in Fig.5.

Table 1. The results of tensile tests conducted on the jute yarn skeins after various chemical surface treatment

\begin{tabular}{|c|c|c|c|c|c|c|c|}
\hline \multicolumn{2}{|c|}{ Treatment duration, hours $\rightarrow$} & 0 & 0.5 & 1 & 2 & 4 & 6 \\
\hline $\begin{array}{c}\text { Reacting } \\
\text { substance } \downarrow\end{array}$ & $\begin{array}{c}\text { Mass concentration of Reacting } \\
\text { substance in a solution, \% }\end{array}$ & \multicolumn{3}{|c|}{ Rupture force of yarn skein in static tensile test, N } \\
\hline Untreated jute & - & $42.0 \pm 5.6$ & - & - & - & - & - \\
\hline \multirow{3}{*}{$\mathrm{NaOH}$} & 1 & - & $32.7 \pm 3.3$ & $33.1 \pm 2.0$ & $33.4 \pm 2.9$ & $34.1 \pm 3.8$ & $36.5 \pm 4.1$ \\
\cline { 2 - 8 } & 3 & - & $34.5 \pm 2.9$ & $34.9 \pm 2.8$ & $39.9 \pm 1.6$ & $36.8 \pm 2.2$ & $36.9 \pm 4.1$ \\
\cline { 2 - 8 } & 5 & - & $35.8 \pm 3.1$ & $35.1 \pm 3.0$ & $40.1 \pm 3.9$ & $37.7 \pm 4.5$ & $37.6 \pm 3.3$ \\
\hline \multirow{3}{*}{$\mathrm{KOH}$} & 15 & - & $21.9 \pm 3.7$ & $24.2 \pm 4.5$ & $23.2 \pm 4.6$ & $18.8 \pm 4.2$ & $18.3 \pm 4.8$ \\
\cline { 2 - 8 } & 1 & - & $37.3 \pm 3.7$ & $35.3 \pm 3.6$ & $26.8 \pm 3.6$ & $44.6 \pm 3.0$ & $31.8 \pm 3.5$ \\
\cline { 2 - 8 } & 3 & - & $39.9 \pm 3.2$ & $36.3 \pm 3.5$ & $27.5 \pm 3.1$ & $48.1 \pm 6.9$ & $34.7 \pm 3.7$ \\
\hline Methanol & 5 & - & $29.7 \pm 4.0$ & $23.8 \pm 4.2$ & $24.9 \pm 4.6$ & $24.7 \pm 3.9$ & $25.5 \pm 4.4$ \\
\hline Vinyl acetate & 15 & - & $42.7 \pm 3.9$ & - & - & - & - \\
\hline $\begin{array}{c}\text { Toluene } \\
\text { diisocyanate }\end{array}$ & 100 & - & $43.0 \pm 4.7$ & - & - & - & - \\
\hline
\end{tabular}
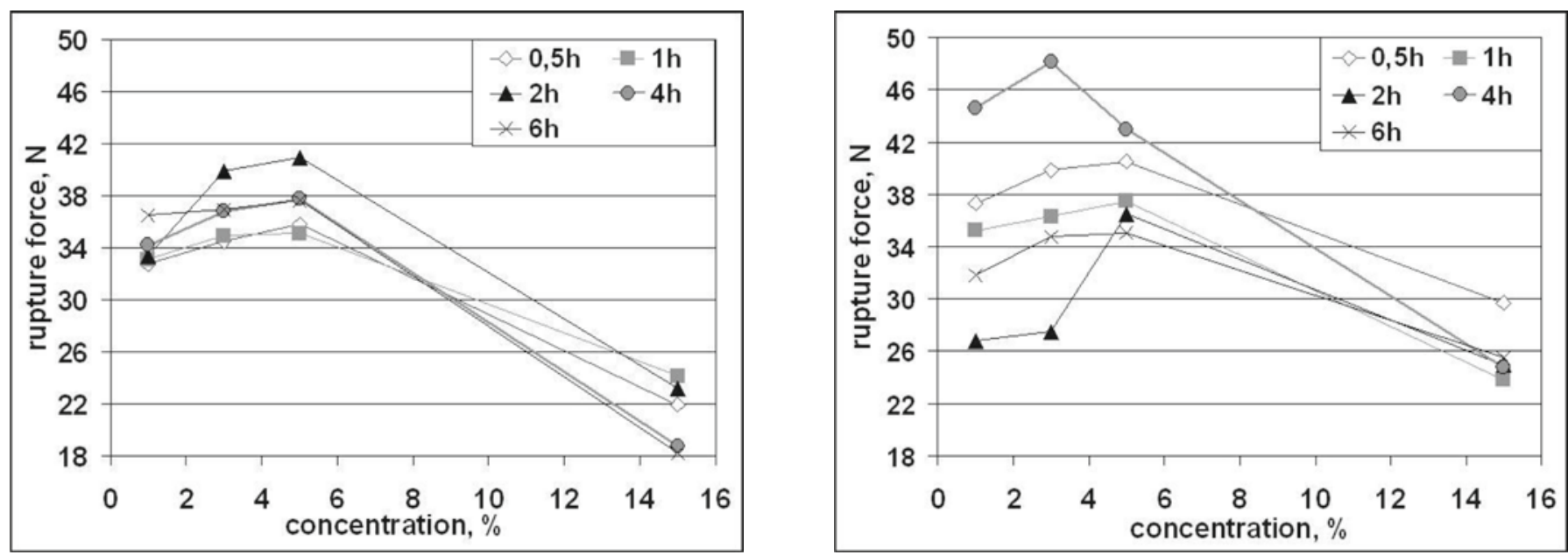

Figure 2. The effect of the $\mathrm{NaOH}(\mathrm{a})$ and $\mathrm{KOH}(\mathrm{b})$ water solution concentration, at various treatment duration, on the rupture force of a jute yarn skein 

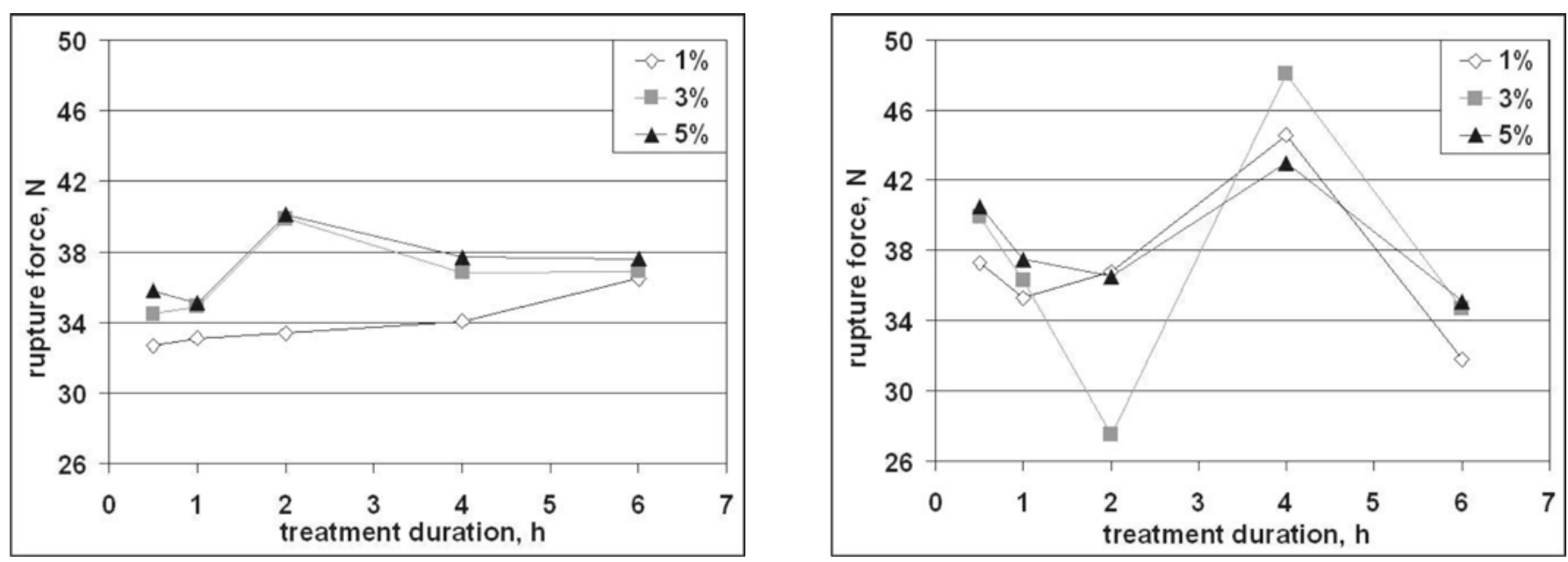

Figure 3. The effect of treatment duration in the $\mathrm{NaOH}$ (a) and $\mathrm{KOH}$ (b) water solutions, at various solution concentration, on the rupture force of a jute yarn skein

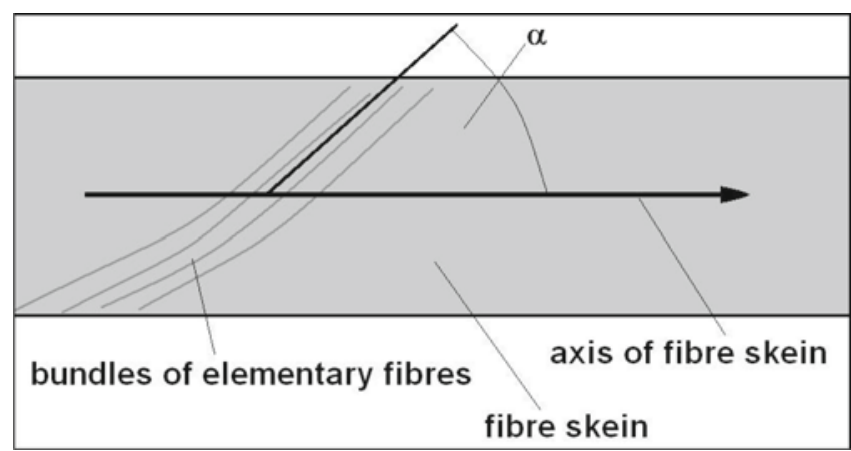

Figure 4. A scheme of the twist angle - the angle between the main axis of fibre macro-skein and bundles of elementary fibres

\section{RESULTS AND DISCUSSION}

The results of tensile tests conducted on the yarn skeins after various chemical treatment are presented in the Table 1 . The results of profilographometric measurements of fibre twist angle and yarn diameter are shown in Fig.6 and 7.

The digital pictures of the representative area of the untreated and treated $(1 \% \mathrm{KOH}$ water solution by $1 \mathrm{~h})$ jute fabric made with the use of profilographometer are introduced in Fig.8.

The yarn rupture force versus the substance mass concentration and versus the treatment duration diagrams are shown in Fig.2 and 3.

The yarn rupture force after the treatments is lower no more than about $5-20 \%$, in comparison with that of untreated jute. Such decrease does not eliminate the treated yarn from composite technology. Moreover, it is expected that the treatments will give improvement in technological properties of the fabric and in mechanical performance of the composites due to assurance of better wettability and permeability of the fibres.

Former studies showed as the rule that alkali treatment makes some deterioration in mechanical properties of natural fibres but finally improves the mechanical performance of the manufactured composites.

The example may be the study concerning flax fibre - epoxy composites. After the treatment in $\mathrm{NaOH}$ water solution decrease in tensile strength of the fibres was observed: by about $50 \%$ for $1 \%$, by about $28 \%$ for $2 \%$ and by about $20 \%$ for $3 \%$. However, it does not correspond with the manufactured composites strength
- flexural strength of them was higher, in comparison with the ones made of the untreated fibres by: $9 \%$ for $1 \%$ $\mathrm{NaOH}, 20 \%$ for $2 \% \mathrm{NaOH}$ and $30 \%$ for $3 \% \mathrm{NaOH}^{13}$.

It confirms the rule that the decrease in natural fibre performance does not result in decrease in final composite performance. Its explanation may be a simultaneous improvement in bond strength between the fibre and the matrix, which strongly improves the composite performance (even though some weakening of the fibres).

In the study concerning sisal fibres treated with $\mathrm{NaOH}$ solution and $\mathrm{N}$-isopropyl acrylamide it was found that tensile strength of fibres is higher after the treatment in $2 \% \mathrm{NaOH}$ by about $16 \%$ whilst shear strength (pull-out tests) is higher by about $165 \%{ }^{14}$.

The example of the advantageous effect of chemical treatment on the mechanical performance of composite may also be the study on bagasse fibre - biodegradable polyester composite. Improvement in tensile strength by about $13 \%$ was observed after the treatment in $1 \%$ $\mathrm{NaOH}$ water solution ${ }^{15}$.

Clearly a higher rupture force was observed for $3 \%$ and $5 \%$ treatments in $\mathrm{NaOH}$ and in $\mathrm{KOH}$ as well, in comparison with $1 \%$ treatments (Fig.2). Treatment in 15\% $\mathrm{NaOH}$ and $\mathrm{KOH}$ water solutions severely reduces the yarn rupture force - by about $40-50 \%$, when compared with the untreated jute yarn. Therefore it is unlike to apply such strong solutions for natural fibres preparation in composites technology.

For the $\mathrm{NaOH}$ solution the treatment duration resulting in the best yarn rupture force is $2 \mathrm{~h}$ (Fig.3). For the $\mathrm{KOH}$ solution the optimal duration is $4 \mathrm{~h}$. Longer duration leads to stabilization or even decrease in the yarn rupture force. Only the low-concentrated $(1 \%) \mathrm{NaOH}$ solution shows permanent increase in yarn rupture force with treatment duration, but the increase is very slight (Fig.3a).

It is necessary to consider as optimal conditions of alcali-treatment: $5 \%$ concentration and $2 \mathrm{~h}$ duration for $\mathrm{NaOH}, 3 \%$ concentration and $4 \mathrm{~h}$ duration for $\mathrm{KOH}$.

In the study concerning sugar palm fibre - epoxy composite improvement in composite tensile modulus was observed (only little increase in tensile strength). The positive effect took place only up to $4 \mathrm{~h}$ of treatment duration ${ }^{12}$.

Two effects were observed which can explain the 

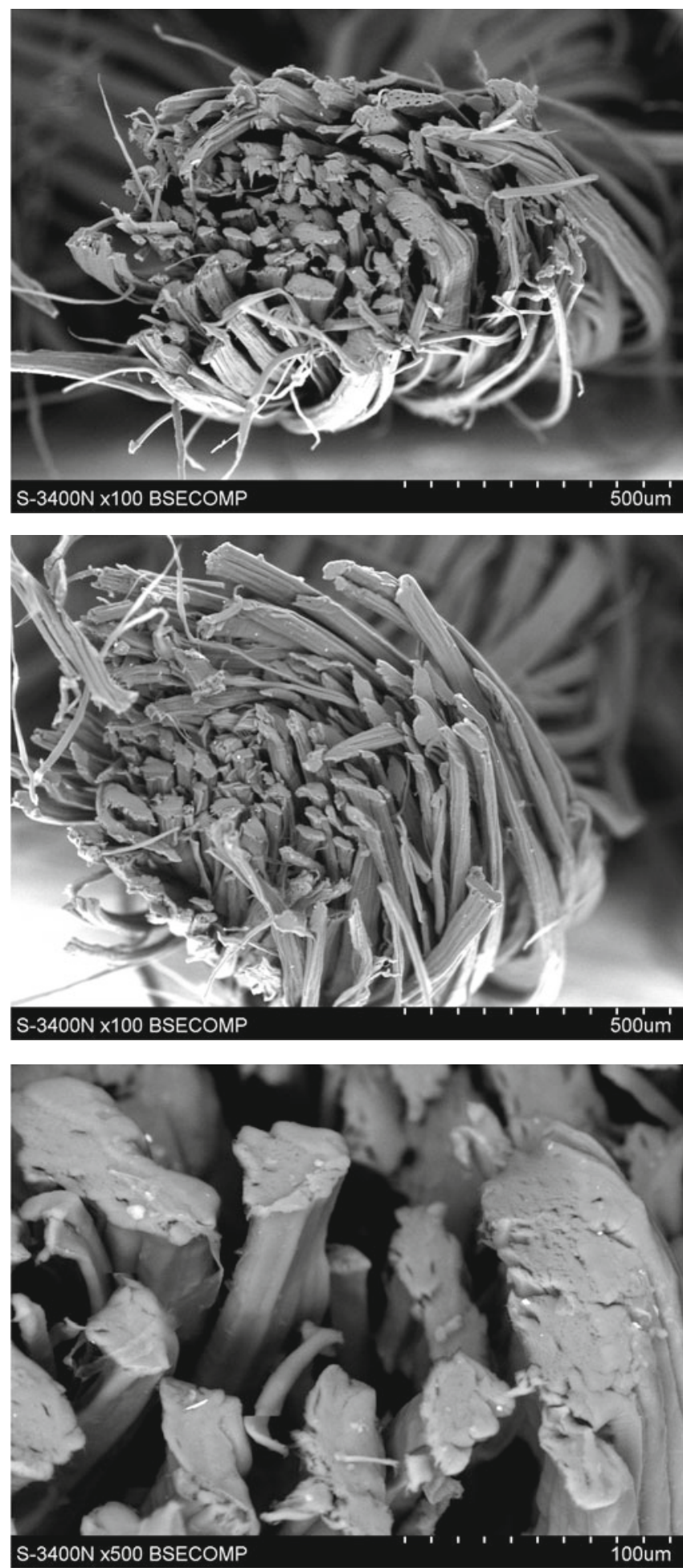
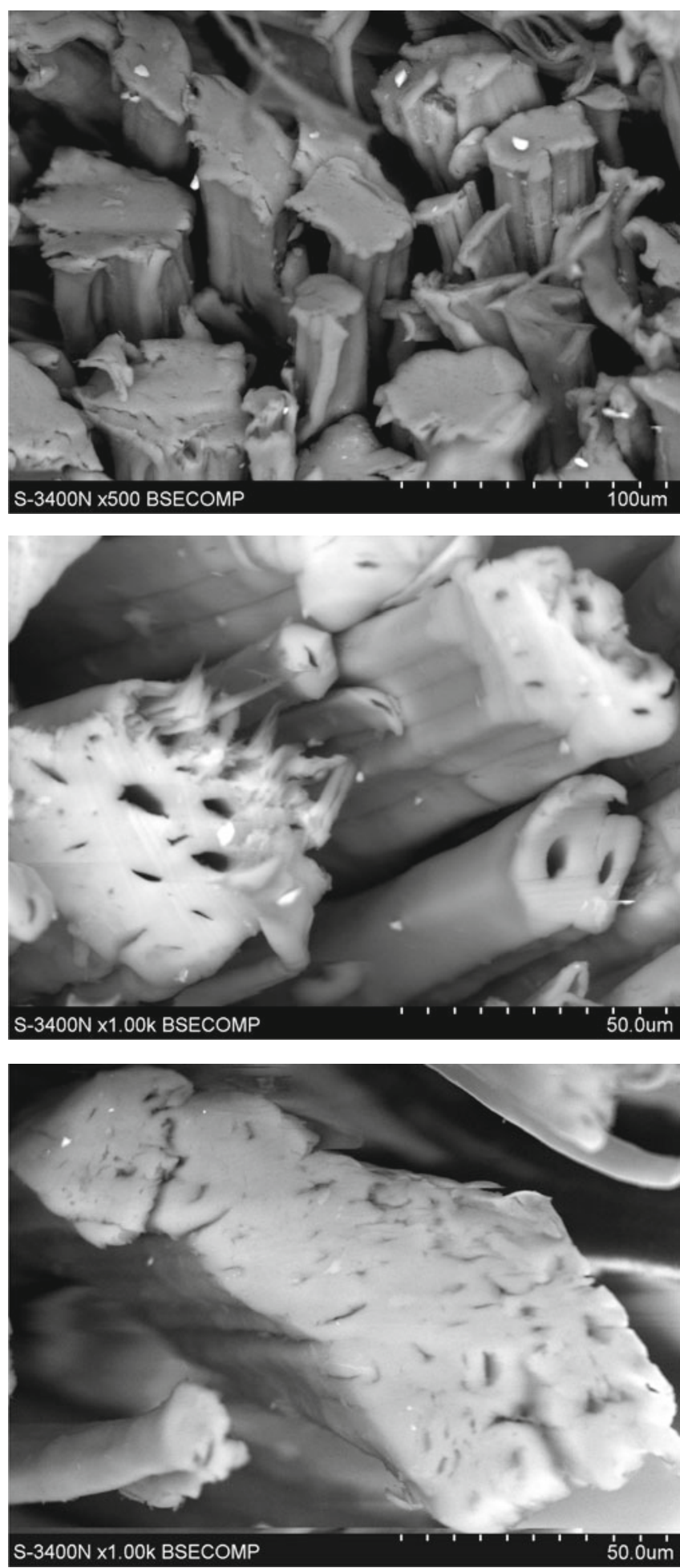

Figure 5. Microphotographs of the yarn structure and elementary cellulose fibres (device: Hitachi S-3400N scanning electron microscope). A, C, E- untreated jute; B, D, F - jute treated with $1 \% \mathrm{KOH}$ water solution by $1 \mathrm{~h}$

influence of chemical treatment on the mechanical performance of jute yarn: swelling and change in the orientation of elementary fibres. The swelling was evaluated by measure of average diameter of a yarn skein. The results of the diameter measurements are presented in Fig. 3. The change in the orientation of elementary fibres was evaluated by measure of average fibre twist angle (to the skein's axis). The results of the twist angle measurements are presented in Fig. 6.

The effects of swelling and change in the twist angle of elementary fibre bundles before and after the treatment is also visible in Fig. 8 - compare A and B pictures.

Practically for the all applied treatments a notable yarn swelling was observed. Swelling mechanism consists in that polar molecules, among others: water in $\mathrm{NaOH}$ and $\mathrm{KOH}$ solutions, methanol, toluene diisocyanate, vinyl acetate, adsorb on a cellulose surface, leading to structural changes.

In many areas adsorption of polar molecules leads to debonding of the hydrogen bonds bonding the cellulose bands. Such molecules cause the debonding and join to the cellulose bands surfaces themselves. During the exsiccation process most of the molecules debonds off the cellulose surface. However, primary bonds are not reproduced and the structure remains stably deformed on all superstructure levels, which is macroscopically observed as a swelling. The profilogrphometric digital pictures (exemplary pictures in Fig. 8) analysis allow 


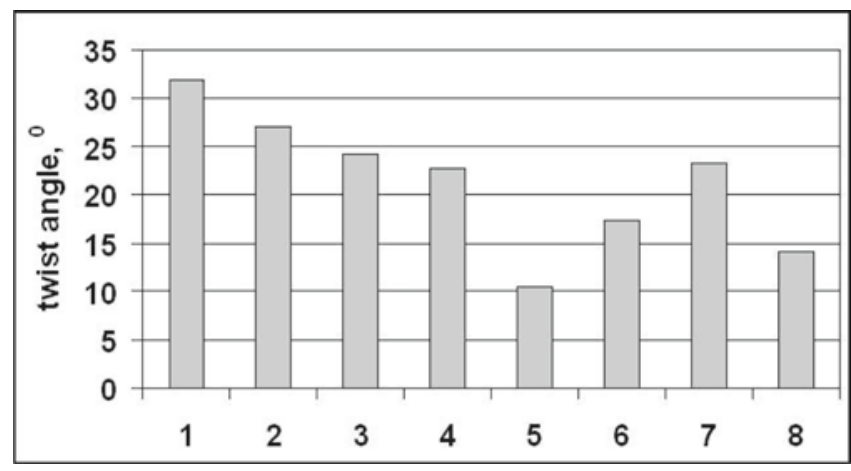

Figure 6. Average twist angle between the elementary fibre bundle and the yarn skein's axis for jute after treatment with various substances by various immerse duration: 1 - untreated, $2-\mathrm{KOH} 1 \%$, 0.5h, $3-\mathrm{KOH} 1 \%, 1 \mathrm{~h}, 4-\mathrm{KOH} 1 \%$, 6h, $5-\mathrm{KOH} 15 \%$, $0.5 \mathrm{~h}, 6$ - toluene diisocyanate, $0.5 \mathrm{~h}, 7$ - methanol, $0.5 \mathrm{~h}, 8$ - vinyl acetate, $0.5 \mathrm{~h}$
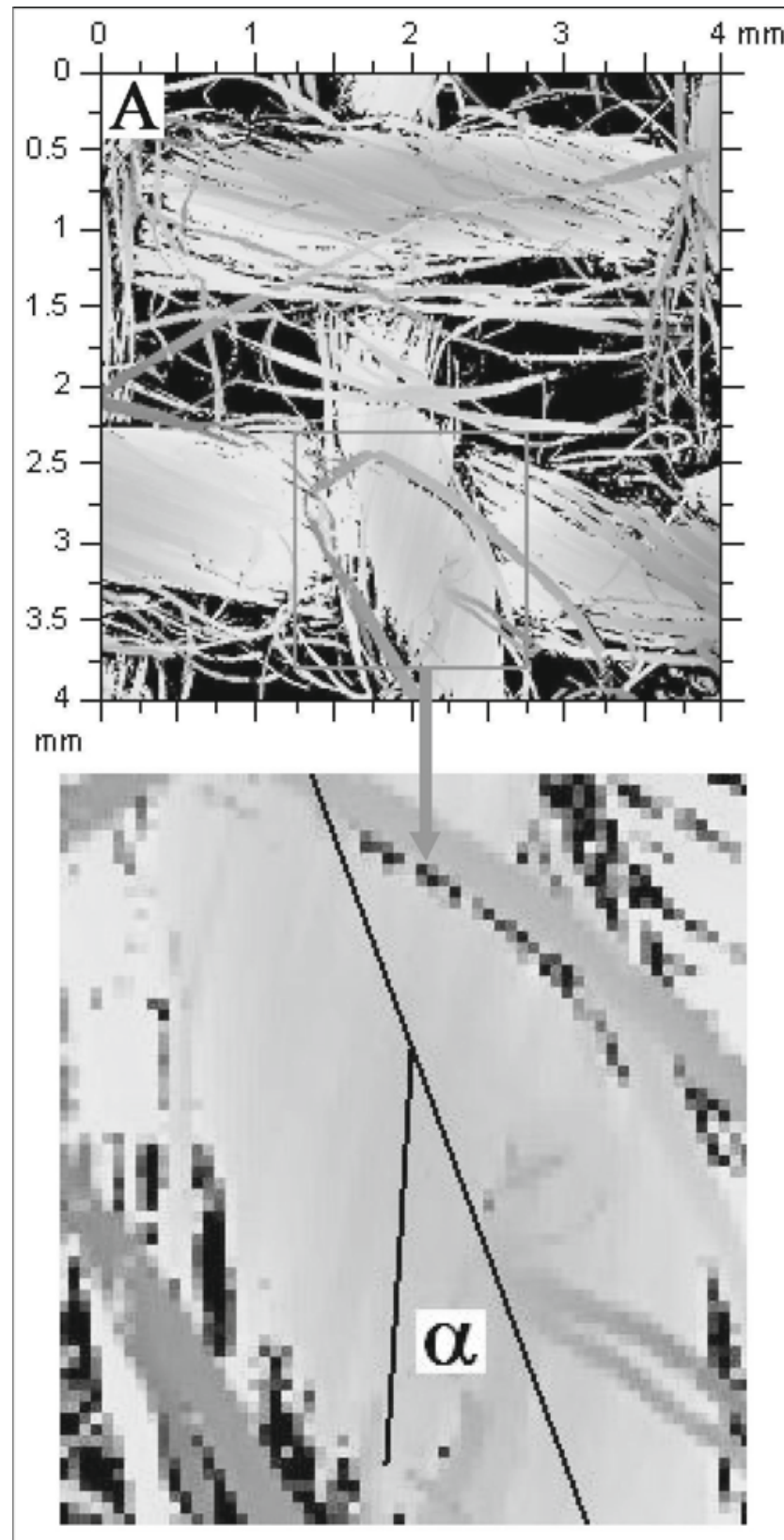

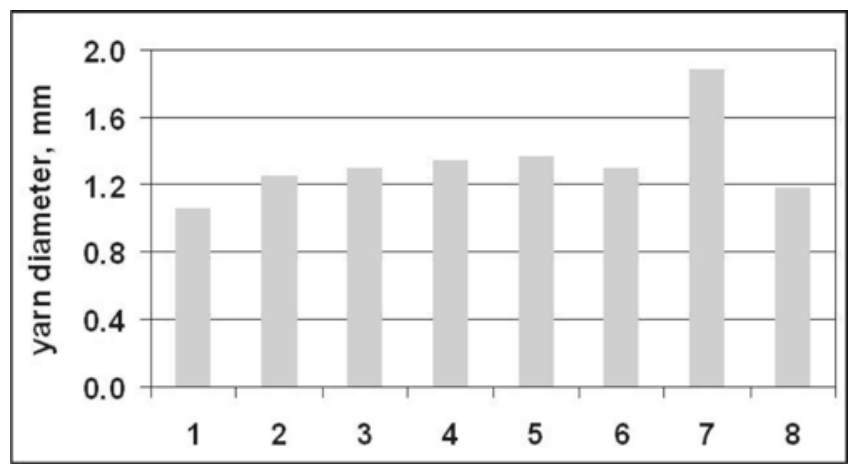

Figure 7. Average diameter of the jute yarn skein after the treatment with various substances by various immerse duration: 1 - untreated, $2-\mathrm{KOH} 1 \%, 0.5 \mathrm{~h}$, $3-\mathrm{KOH} 1 \%, 1 \mathrm{~h}, 4-\mathrm{KOH} 1 \%$, 6h, $5-\mathrm{KOH} 15 \%$, $0.5 \mathrm{~h}, 6$ - toluene diisocyanate, $0.5 \mathrm{~h}, 7$ - methanol, $0.5 \mathrm{~h}, 8$ - vinyl acetate, $0.5 \mathrm{~h}$
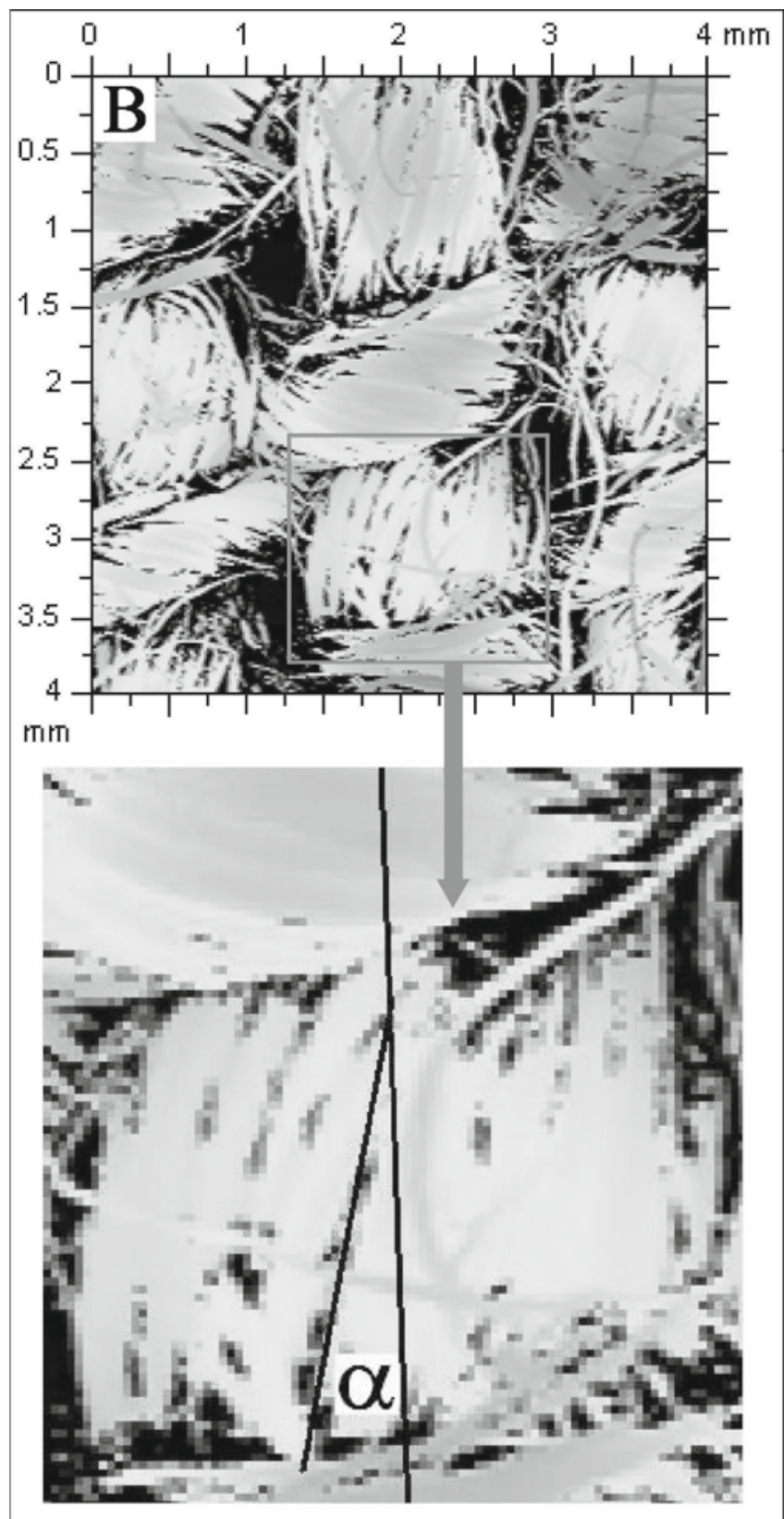

Figure 8. Digital pictures of the representative area of untreated jute fabric (A) and the fabric treated with $1 \% \mathrm{KOH}$ water solution by $1 \mathrm{~h}$. The difference in the twist angle of elementary fibre bundles $(\alpha)$ before and after the treatment is visible 
to state that the average diameter has increased by $20 \div 100 \%$ (Fig. 7). However, individual investigations with the use of scanning electron microscope (SEM) allowed to observe that the diameter of jute elementry fibre increased from 36 to $59 \mu \mathrm{m}$ (increase by about $65 \%$ ) after treatment in $3 \% \mathrm{NaOH}$ water solution by $0.5 \mathrm{~h}$. Exemplary micrographs presented in Fig.5 also confirm the swelling of the yarn - when compare Fig. 5E and $5 \mathrm{~F}$ decreases in the diameter of "empty canals" running along the bundles are visible. The decrease is doubtless caused by the swelling of the bundle. It proves that the swelling process takes place just at the very low level of cellulose structure and that it almost certanly follows the formerly described debonding of the hydrogen bonds between the cellulose bands in numerous areas. The grade of the yarn swelling is without doubts dependent on the polarity of treatment substances and on the dimensions of their molecules. More polar reacting substance will probably penetrate bigger area inside the structure in comparison with the less polar substance and will cause a higher grade of swelling (eg. Compare the diameter of jute yarn after the treatment with less polar vinyl acetate and that after the treatment with more polar methanol - Fig.7). Polar reacting substance having big molecule dimensions will cause bigger structure deformation after the "enter" between the cellulose bands, however it will need bigger interaction forces to do it and probability of the penetration will be appropriately lower. For instance, the swelling grade after treatment in toluene diisocyanate (relatively big molecules; molecular weight of about $174 \mathrm{u}$ ) is bigger than after the treatment in vinyl acetate (molecular weight of about $86 \mathrm{u}$ ), but it is significantly lesser than in strongly polar methanol (molecular weight of about only $32 \mathrm{u}$ ) - Fig.7. However, the high viscosity of the diisocyanate must be taken into consideration, which additionally makes penetration of the yarn difficult. The swelling of the yarn causes decrease in its internal bonding forces (desizing) and deterioration in its internal state of stress, which leads to decrease in mechanical performance. Enlargement and opening of pores occurs, which causes that they easily fill with a resin during the laminate manufacturing process.

Change in the orientation of elementary fibres, measured as the change of their twist angle within yarn skein, results undoubtedly from the swelling effect and from the structural changes of the fibres - among other shortening of the fibres. It was observed that the twist angle decreases with the treatment duration and with the concentration of alkaline solutions (Fig. 6). It testifies that besides the swelling process, the twist angle is also influenced by the proceeded chemical reactions. In Fig. 9 the diagram of the relationship between the yarn rupture force and the twist angle of yarn's elementary fibres is presented.

Untreated jute, yarn after $1 \% \mathrm{KOH}$ treatment with various duration $(0.5,1$ and $6 \mathrm{~h}), 15 \% \mathrm{KOH} 0.5 \mathrm{~h}$ duration and the organic treatments are considered in the diagram.

It is necessary to mark that the twist angle is only one of many factors affecting the strength of the yarn and the relationship in Fig. 9 should not be considered as showing the fullness of the strength changes. However, it allows to notice an evident trend of growth in the

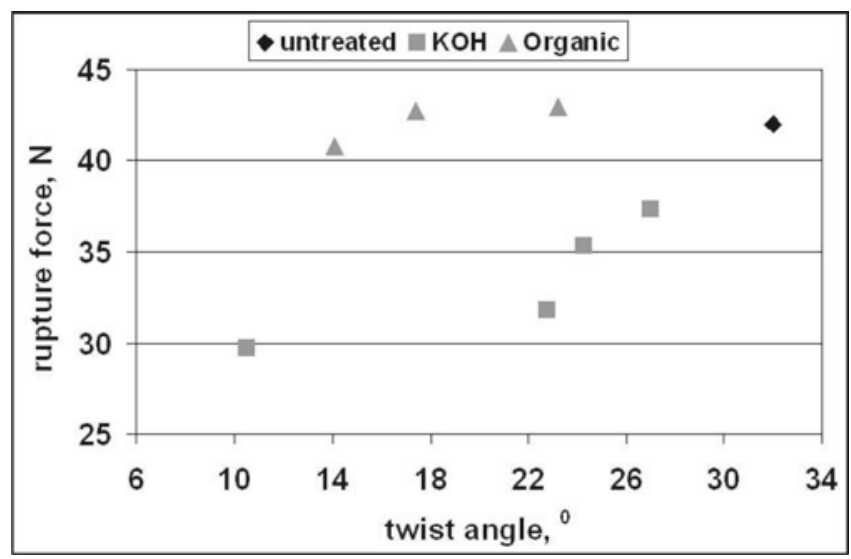

Figure 9. Relationship: jute yarn rupture force versus twist angle of the yarn elementary fibres

rupture force of the yarn with growth in the twist angle of the fibres. In compatibility with the fibrous composite reinforcing theory (a yarn skein may be considered as a composite reinforced with discontinuous fibre) strightening of the fibres (decrease in the twist angle) should cause an increase in yarn strength ${ }^{\mathbf{1 0}}$. However, yarn is a structure based on adhesive and mechanical join of numerous short elementar fibres. Decrease in the twist angle of these fibres leads to weakening of the global "mechanical component" of such join, rather not affecting its "adhesive component" (it changes due to other effects of the chemical treatment). Changes in the twist angle have been allready observed in former researches. In the former study ${ }^{9}$ it was found that after the treatment in $5 \% \mathrm{MgOH}_{2}$ water solution, the twist angle of elementary fibres in jute yarn skein changed from $33^{\circ}$ to $18^{\circ}$. A detailed description of the method of determination of the twist angle using profilographometer has been also included in the study?

Besides the swelling process and the change in the twist angle of elementary fibres, during treatment jute yarn with the alkaline solutions and the organic agents appropriate chemical reactions proceed between a cellulose and the reacting substances.

Advantageous (for the impregnation of the yarn with polymer resin) change of a cellulose structure follows replacement of a part of relatively little hydrogene atoms by big $\mathrm{Na}$ and $\mathrm{K}$ ones. The deformed areas with weakened hydrogene bonds occurs, which facilitates penetration for liquid polymers. Such configuration change has been observed formerly and its advantageous effect on the interactions between some types of natural fibres and some polymers ${ }^{\mathbf{1 , 4}}$ have been found. The effects observed within a framework of this study: yarn swelling, change of the twist angle, change in mechanical performance of the yarn (Fig.2, 3, 6 and 7), may testify the proceeding of chemical reactions. The water solution $3 \%$ for $\mathrm{KOH}$ and $3-5 \%$ for $\mathrm{NaOH}$ should be acknowledged as an optimal concentration. Higher concentration of the solution $-15 \%$ for $\mathrm{NaOH}$, only as low as $5 \%$ for $\mathrm{KOH}$ - causes a strong decrease in the yarn rupture force, which proves a significant degradation of the structure by high concentrated bases. The particular tendency to swell the yarn by high concentrated bases (Fig.7) arises from the substitution of bigger, in comparison with the less concentrated ones, amount of little hydrogene atoms in cellulose with larger $\mathrm{Na}$ or $\mathrm{K}$ atoms. 
Methanol is strong proton dissolvent, what causes its especial susceptibility to swell cellulose yarn (Fig.3). As an organic dissolvent, methanol clears the yarn structure of impurities, such as wax finishes remains. It gives the methanol additional the possibility of penetration.

Vinyl acetate and toluene diisocyanate are the polymer precursors. After joining a cellulose they may become the specific "interbonds" between the cellulose and polymer resins used in composite impregnation processes. They even may copolymerize with the resins.

Toluene diisocyanate is a polar substance with very high chemical reactivity (much higher than that of polyester or epoxy resins) and, at the same time, relatively high viscosity. During treatment it intensively penetrates and often encloses pores in the yarn structure. Such behaviour partly levels the effects of swelling and results in the smoothing and levelling of the yarn surface.

The observed effects after treatment in the organic substances reveal that chemical and physical interaction takes place rather only at the surface or near the surface area.

However, in former studies it was found that some of organic treatments also affect the inner structure of the cellulose (acting not only within a surface) - for example, the improvement in crystallinity index from 72 for untreated sisal fibre to about 78 for treated with $\mathrm{N}$-isopropyl acrylamide ${ }^{\mathbf{1 4}}$.

Additional confirmation may be the study concerning acrylate-grafted henequen fibres where the $32 \%$ growth in the fibre tensile strength and the $18,5 \%$ growth in crystallinity of the fibres was observed ${ }^{\mathbf{1 6}}$.

\section{CONCLUSIONS}

It was found that chemical treatment of jute yarn using: $\mathrm{NoOH}$ and $\mathrm{KOH}$ solutions not stronger than 5\%, methanol, vinyl acetate, toluene diisocyanate do not cause significant changes (especially decrease) in yarn mechanical performance. Among the tested alkaline treatments $3 \% \mathrm{KOH}$ solution by $4 \mathrm{~h}$ treatment duration seems to be especially promising - it gives about $10 \%$ growth in yarn rupture force. Potentially applicable in composite technology are also vinyl acetate and toluene diisocyanate - interaction with them practically does not negative influence on the mechanical performance of the yarn.

Considering the application of natural fibres as the reinforcements in composite materials it is necessary to emphasize that the proposed surface treatment processes do not make significant changes in the mechanical performance of the yarn. Transformations of the fibres structure may contribute to the improvement in the quality of their coupling with polymer matrix and ensure better infiltration of the resin in the fibre reinforcement structure. It will result in a better quality of the composite material and shortening of its manufacturing duration.

\section{ACKNOWLEDGEMENTS}

This work is partially financed by the Ministry of Science and Higher Education of the Republic of Poland in the project N N508 440936.

\section{LITERATURE CITED}

1. Bledzki, A. \& Gassan, J. (1999). Composites reinforced with cellulose fibres. Prog. Polymers. Sci. 24, 221-274.

2. Williams, G.I. \& Wool, R.P. (2000). Composites from natural fibers and soy oil resins. Appl. Compos. Mater., 7, 421-32.

3. Sinha, E. \& Rout, S.K. (2009). Influence of fibre-surface treatment on structural, thermal and mechanical properties of jute fibre and its composite. Bull. Mater. Sci., 1, 65-76.

4. Gassan, J. \& Bledzki, A. (1999). Possibilities for improving the mechanical properties of jute/epoxy composites by alkali treatment of fibres. Comp. Sci. and Techn., 59, 1303-1309.

5. Khan, F. \& Ahmad, S.R. (1996). Chemical modification and spectroscopic analysis of jute fibre. Pol. Degr. and Stab., $52,335-340$.

6. Sgriccia, N. \& Hawley, M.C. (2007). Thermal, Morphologi$\mathrm{cal}$, and electrical characterization of microwave processed natural fiber composites. Comp. Sci. and Techn., 66(9), 1986-1991.

7. Sapieha, S., Verreault, M., Klemberg-Sapieha, J. E., Sacher, E., Wertheimer, M.R. (1990). X-ray photoelectron study of the plasma fluorination of lignocellulose. Appl. Surf. Sci., 2, 165-169.

8. Van den Oever, M.J.A, Bos H.L. \& van Kemenade, M.J. J.M. (2000). Influence of the physical structure of flax fibres on the mechanical properties of flax fibre reinforced polypropylene composites. Appl. Comp. Mat., 7, 387-402.

9. Bogdan, A., Myalski, J., Wieczorek, J. \& Koziol, M. (2009). Influence of chemical treatments for structure and mechanical properties of jute fibres used for polymer - matrix composite producing. Kompozyty, 4, 358-362 (in Polish).

10. Hyla, I. \& Sleziona, J. (2004). Composites. Elements of mechanics and design. Wydawnictwo Politechniki Slaskiej, Gliwice (in Polish).

11. Mastalerz, P. (1986). Organic chemistry. PWN, Warszawa (in Polish).

12. Bachtiar, D., Sapuan, S.M. \& Hamdan, M.M. (2008). The effect of alkaline treatment on tensile properties of sugar palm fibre reinforced epoxy composites. Mat. and Des., 29, 1285-1290 DOI: 10.1016/j.matdes.2007.09.006.

13. Van de Weyenberg, I., Truong, T.C., Vangrimde, B. \& Verpoest, I. (2006). Improving the properties of UD flax fibre reinforced composites by applying an alkaline fibre treatment. Comp.: Part A, 37, 1368-1376, DOI: 10.1016/j. compositesa.2005.08.016.

14. Sydenstricker, T.H.D., Mochnaz, S., Amico, S.C. (2003). Pull-out and other evaluations in sisal-reinforced polyester biocomposites. Pol. Tes., 22, 375-380, DOI: 10.1016/S01429418(02)00116-2.

15. Cao, Y., Shibata, S., Fukumoto, I. (2006). Mechanical properties of biodegradable composites reinforced with bagasse fibre before and after alkali treatments. Comp.: Part A, 37, 423-429, DOI: 10.1016/j.compositesa.2005.05.045.

16. Canche-Escamilla, G., Cauich-Cupul, J.I., Mendizabal E., Puig, J.E., Vazquez-Torres, H. \& Herrera-Franco P.J. (1999). Mechanical properties of acrylate-grafted henequen cellulose fibers and their application in composites. Comp.: Part A, 30, 349-359. 